\title{
Ouvir ou ver por espelhos: a retórica de Vieira e de Bach
}

\author{
Henrique Romaniello Passos
}

Resumo

\begin{abstract}
Tentando manipular o turbilhão do real, a retórica de Vieira e Bach acomoda o mundo no formato do espelhamento, através de uma confortável simetria que permite que o fugaz seja controlado. O virtuosismo desses dois mestres mostra como a repetição e a diferença podem conviver num projeto de explicação do mundo.
\end{abstract}

Palavras-chave: Vieira. Bach. Retórica. Espelhamento.

A estratégia do espelhamento é um recurso bastante produtivo na economia sermonária de Vieira e nos procedimentos fugáticos de Bach, característica comum que desvela outros tantos pontos de contato numa notável aproximação intersemiótica, razão de ser desse trabalho. Além da clássica referência ao Sermão da Sexagésima, outras prédicas são mencionadas ao longo do trajeto de cotejamento com as fugas do músico alemão, e mais detidamente com as chamadas "fugas-espelho".

O projeto político subentendido em Vieira - a realização do Quinto Império de Cristo em Portugal - encontrou plena acomodação em sua "sala de espelhos" retórica, engenhoso e agudo artifício aliado ao princípio do conceito predicável. O termo é de João Mendes, o mesmo que identifica na predicação do padre luso-brasileiro uma "estética do espelho", em que uma dada circunstância do mundo material é posta para corresponder a uma imagem ou ocorrência na Sagrada Escritura, um duplo exemplar menos fornecido pelo texto bíblico do que selecionado pelo sermonista:

[E]stamos num âmbito misterioso, numa espécie de sala de espelhos, onde os destinos se respondem como ecos ou rebrilham como reflexos. Desse simultaneísmo, Ihe chamámos também, revertem, para a estrutura e andamento do sermão vieirense, conseqüências múltiplas: quanto à sua estrutura, que não será lógica, mas analógica; quanto ao processo do "exemplo", que predomina sobre dedução; e quanto ao desenvolvimento vagaroso, que só o será na aparência. [...] E quando falamos em "estética do espelho", não nos referimos somente à freqüência do tema e do termo "espelho", que anda também presente nas artes plásticas do Barroco; nem ao facto de Vieira ter um sermão inteiro às religiosas de Odivelas, a exortá-las a que ponham de parte os espelhos que são o "demónio mudo" da sua vaidade. Referimo-nos a uma visão diádica do universo, à tendência a tudo ver em analogia e "exemplo" (MENDES, 1970, p. 431).

Alcir Pécora (1994, p. 159) repõe a questão em seus termos, sem, no fundo, discordar de Mendes. Os desígnios divinos estariam inscritos nos eventos da realidade terrena, Deus historiografaria sua vontade na vida dos homens traçando o curso dos fatos (quase) anonimamente. Caberia ao orador a tarefa de revelar essa presença oculta, isto é, de "desempenhar" esse mistério explicando o significado sacro das ocorrências e desenvolvendo uma tese de trabalho muito particular: aquela que, 
supostamente atendendo aos interesses de Deus, atenderia, na verdade, aos interesses daquele que a propõe. A Bíblia, para ele, é um depósito de exemplos potencialmente especulares à espera do "correto" manuseio para se transformarem em imagens virtuais da matéria analisada. Nessa exegese, decorrente da aplicação do conceito predicável, a vida está espelhada e explicada nas Escrituras e vice-versa, isto é, a Divina Providência se materializa no cotidiano dos indivíduos, nas circunstâncias que os cercam, nelas se escondendo e através delas se revelando. A definição de Saraiva (1969, p. 518-519) sobre o conceito predicável é bastante elucidativa quanto a sua plasticidade:

O sermão [de Vieira] desenvolve-se, como hoje, a partir do "conceito predicável", ou seja, um texto bíblico que se comenta de acordo com o tema e as teses que o orador se propõe a desenvolver. Para Vieira o texto contém um mistério a decifrar, ou, como se diz na terminologia do tempo, a "desempenhar". [...] Ora este "desempenho" não consistia num comentário moral e doutrinal dentro do senso-comum, tomando em conta o conjunto do episódio a que pertence o texto, o seu conteúdo perceptivo etc., mas sim em considerar isoladamente o texto, a considerar a pretensa etimologia das palavras, a sua posição na frase, as repetições, o número de sílabas e letras de que se compõem, os seus vários significados, o jogo de sinônimos e antônimos, a essência dos objetos significados etc. [...] Esta forma de discurso pressupõe que há uma relação substancial, não convencional, entre a palavra e a coisa significada.

A Palavra de Deus e a existência humana, nessa visão, fariam parte de um circuito fechado. Um corrobora o outro, um mostra, reflete o outro. Nem mesmo o tempo escaparia dessa armadilha. Para Vieira, passado e futuro estariam metaforizados nos espelhos recíprocos de Salomão, os quais, voltados um para o outro, gerariam infinitos reflexos do mesmo: o Antigo Testamento anuncia o Novo, e este é uma consubstanciação daquele. E o tempo presente? O presente é o momento em que se percebe essa reflexão simultânea (ou simultaneísmo, no dizer de João Mendes). A citação extraída do Sermão da Quarta-feira de Cinzas, de 1670, é coletada por Pécora (1995, p. 303):

Nesta mesma roda natural das coisas humanas, descobriu a sabedoria de Salomão dois espelhos recíprocos, que podemos chamar do tempo, em que se vê facilmente o que foi e o que há de ser $[\ldots]$. Que é o que foi? Aquilo mesmo que há de ser. Que é o que há de ser? Aquilo mesmo que foi [...]. Ponde estes dois espelhos um defronte do outro, e assim como os raios do ocaso ferem o oriente e os do oriente o ocaso, assim, por reverberação natural e recíproca, achareis que no espelho do passado se vê o que há de ser, e no do futuro, o que foi. Se quereis ver o futuro, lede as histórias e olhai para o passado; se quereis ver o passado, lede as profecias e olhai para o futuro. E quem quiser ver 0 presente, para onde há de olhar? Não o disse Salomão, mas eu o direi. Digo que olhe juntamente para um e para outro espelho. Olhai para o passado e para o futuro, e vereis o presente.

Vieira escolheu o Sermão da Sexagésima para figurar como o primeiro de sua longa série sermonária. Não é para menos: a Sexagésima é o sermão que trata da elaboração do sermão: metasermão, portanto, e nada mais justo que ele funcione como uma espécie de modelo para todos os que se lhe seguem, além de operar como a especularidade dentro de si mesmo - prédica que espelha prédica. $O$ espelhamento ocorre tanto no plano do enunciado quanto no da enunciação.

O orador português radicado na Bahia não poupa palavras para categorizar sua função de pregador. Vieira se diz (ou melhor, diz do pregador) espelho da luz de Deus, intermediário da Graça Divina junto aos homens.

Fazer pouco fruto da palavra de Deus no mundo pode proceder de um de três princípios: ou da parte do pregador, ou da parte do ouvinte, ou da parte de Deus. Para uma alma se 
converter por meio de um sermão há de haver três concursos: há de concorrer o pregador com a doutrina, persuadindo; há de concorrer o ouvinte com o entendimento, percebendo; há de concorrer Deus com a graça, alumiando. Para um homem se ver a si mesmo são necessárias três coisas: olhos, espelho e luz. Se tem espelho e é cego, não se pode ver por falta de olhos; se tem espelho e olhos, e é de noite, não se pode ver por falta de luz. Logo há mister luz, há mister espelho, e há mister olhos. Que coisa é a conversão de uma alma senão entrar um homem dentro de si, e ver-se a si mesmo? Para esta vista são necessários olhos, é necessário luz, e é necessário espelho. O pregador concorre com 0 espelho, que é a doutrina; Deus concorre com a luz, que é a graça; o homem concorre com os olhos, que é o conhecimento. Ora suposto que a conversão das almas por meio da pregação depende destes três concursos: de Deus, do pregador e ouvinte; por qual deles havemos de entender que falta? Por parte do ouvinte, ou parte do pregador, ou por parte de Deus? (VIEIRA, 2003, p. 33).

Superfície refletora, superfície inversora, estratégia de conversão. Quando se adentra a arquitetura de sua sala de espelhos, o que se vê é a multiplicação voluptuosa de um mesmo tema em desdobramentos sempre ancorados no ponto inicial, sua tese como rosa abrindo mais e mais pétalas sem deixar de ser a mesma rosa. Cada etapa argumentativa, ao exaurir-se enquanto esforço de resposta ao tema, dá passagem a uma nova possibilidade, a um novo "desempenho" do mistério, e assim sucessivamente, numa expansão do pensamento. Vieira faz sua audiência ir convivendo com soluções provisórias, varando fundos falsos, girando, enfim, na vertigem do mergulho num abismo aparentemente interminável. Quando finalmente o pregador oferece o "gabarito" para sua pergunta-mote, seus ouvintes - cujas inquietações já ganharam voz e espelho no discurso, ao lado das respostas a virtuais opositores - já estão enredados nas articulações do sagaz jesuíta. Ainda dentro do maquinário lógico-afetivo de sua prédica, não se pode deixar de apontar as resignificações etimológicas de nomes de personagens bíblicos e as reinterpretações de trechos já trabalhados, tudo levado a efeito de forma a se ajustar às intenções do proponente. No jogo dos espelhos, a reflexão incessante e disseminada do mote a qualquer custo, uma galeria de variações do mesmo tema. Eis o que diz Mendes (1970, p. 278) sobre a sala de espelhos:

Este mundo de Vieira [...] faz lembrar uma verdadeira sala de espelhos, como as que eram freqüentes nos palácios barrocos: perpétua novidade sem coisas novas. Quem entra, provoca determinados reflexos; outro que entre novos reflexos provocará. Assim é com a Bíblia e a profecia, confronto permanente de toda realidade que lhe seja referida, e resposta de infinitos sentidos à diversa proposta que se Ihe fizer. Os mesmos textos, mais carregados de fascínio barroco, como a estátua de Nabuco ou o carro de Ezequiel, ou a luta de David e de Golias aplicar-se-ão a muito diferentes realidades que neles se reflectem e iluminam.

Metáfora paralela e complementar da qual se serve Mendes é a do andamento textual à maneira de círculos concêntricos na água, a idéia do texto que ondula e vibra sempre em torno de um ponto fulcral, ampliando-se em circunferências de raciocínio em contínua abertura. Affonso Romano de Sant'Anna (2000, p. 156) prefere a imagem da elipse, pelo seu caráter de instabilidade e não-fechamento, e a partir dela sugere uma "orquestração repetitivamente esgalhada e espiralada do raciocínio", em sua análise dos sermões de Vieira. Diferenças à parte, o cerne é o mesmo: a prédica vieiriana desenvolve-se em movimentos orbitais cada vez mais elásticos, muito embora sempre atraídos pelo sol do mote seminal, "perpétua novidade sem nada de novo" (MENDES, 1970, p. 435), modificações da mesma imagem, variações do mesmo tema. Voltemos a João Mendes (op. cit., p. 434) mais uma vez: 
Trata-se, assim, de sermões em parágrafos que podem ir, alguma vez, até 15, à maneira de ondas concêntricas, lançadas como encarecimentos sucessivos, de menor para maior; ou então, ao modo da composição pictórica do Barroco, desenvolvimento em diversos planos de profundidade, indo buscar, ao longe e ao passado, em múltiplos reflexos, o comentário alusivo ao caso presente. [...] [O sermão barroco] vai para uma abundância aparentemente desordenada, com ordem subtil $[\ldots]$.

Por incrível que pareça, a música de Bach não é muito diferente do processo predicador de Vieira. Um primeiro e decisivo ponto de contato é a intimidade de Bach com a retórica, um dos eixos estruturais de sua obra. É Harnoncourt (1993, p. 44-45) que o confirma:

A retórica foi uma das vigas mestras na construção de toda a sua obra. Só que esta ossatura formal de toda a música barroca, desde Monteverdi, representava para Bach muito mais do que simples convenção estilística, empregada de modo mais ou menos inconsciente, por seus contemporâneos. É sabido que Bach construía suas obras conscientemente de acordo com a arte da retórica e que o "discurso dos sons" era para ele a única forma musical (assim o julgava seu amigo, o retórico Birnbaum: "Ele conhece tão profundamente os aspectos e regras que têm em comum a obra musical e a arte da retórica, que não só o ouvimos com grande prazer quando emite as suas profundas opiniões a respeito das similitudes e concordâncias das duas artes, como também admiramos a hábil aplicação que faz das mesmas em suas obras"). Seu círculo de amigos, onde preponderavam professores universitários e, entre eles, os germanistas e os retóricos, bem como os relatos pessoais que ficaram registrados, mostram que Bach cultivou essa matéria de forma intensa e por toda a vida.

A música barroca chegou mesmo a organizar um léxico de figuras retóricomusicais apoiado na terminologia da arte retórica, dado o seu caráter persuasivo, de inoculador das paixões, de vitrine dos afetos. A vertente alemã - diferente da italiana, mais sensorial e estética - mesclou seu "sermão sonoro" luterano, "viva voz do Evangelho", com o processo de retoricização pelo qual passava. A essa mistura já tinham sido acrescentados os princípios matemáticos cósmicos de Boécio, a "tecnicização" das artes e a "humanização" das ciências no Renascimento (com destaque maior para o trivium, o conjunto de disciplinas do qual a retórica fazia parte), e estava pronta a musica poetica, síntese única, própria do Barroco protestante alemão. É nesse cenário em que Bach se insere, e é de onde vêm os elementos que explicam, dentre outras coisas, o projeto retórico presente nas fugas do mestre de Eisenach.

A fuga é um exercício retórico baseado no princípio da imitação de vozes. Inicialmente deflagra-se o "sujeito", a célula máter do procedimento fugático, eixo organizador do qual derivarão linhas melódicas próximas e distantes simultaneamente justapostas, porém defasadas entre si. A seqüência-mote é repetida e transformada em inversões por espelhamento, em "cópias" mais graves ou mais agudas, em distensões e contrações desse inevitável pólo atrativo, núcleo temático que vai sendo "meditado" sob diversas perspectivas. O que se faz é multidizer o sujeito de todas as formas possíveis, testando e provando sua permanência e sua versatilidade: a "tese de trabalho" da fuga demonstra-se em defesas, em refutações e rememorações para fundamentalmente afirmar-se, para finalmente vencer e convencer. O uníssono das vozes acontece apenas no fim, quando a "tese" é reafirmada.

José Miguel Wisnik amplia o espaço de ocorrência das situações de espelhamento para além de um fato isolado em um trecho da fuga, preferindo entender a movimentação das vozes como uma reflexão contínua do sujeito da peça, uma constante estrutural da textura fugática, sem abandonar a dimensão retórica de todo processo. Diz ele que "o que temos é um movimento caleidoscópico em que os 
contrários ecoam entre si e se espelham até se revelarem como reverberações defasadas do mesmo" (WISNIK, 1989, p. 155).

Mais contundente ainda é a existência das "fugas-espelho", curiosíssimos pares simétricos de fugas, reveladores de uma ludicidade que é típica do Barroco. Vales e picos no desenho melódico da fuga rectus, a original, tornam-se picos e vales na inversus, a espelhada, evidenciando uma fantástica inversão geométrica ponto por ponto como se de fato um espelho horizontal refletisse uma cópia "negativa" da composição tomada como referência: "simetria confortadora que faz do desconhecido", do novo, "o reflexo invertido do conhecido" (GENETTE, 1972, p. 39), em que "o Outro dá no Mesmo", diria Gérard Genette (op. cit., p. 21).

Não é difícil identificar, a essa altura, um rol de semelhanças entre os sermões de Vieira e as fugas de Bach. Em ambos os casos dialogam a repetição e a diferença, a disseminação e a recolha dos elementos a partir de uma "matriz genética" ordenadora dessa oscilação, seja ela (a matriz) o mote da prédica ou o sujeito da fuga. Gravitando em argumentações divergentes ou (re)convergindo ao ponto de partida, há um fio condutor que nunca desaparece; ao contrário, guia a audiência até ele através do seu jogo de espelhos, através da multiplicação dos ecos.

O ponto alto dessa comparação está na confluência proposta por Affonso Romano de Sant'Anna. Segundo o escritor, as oposições feitas pelos adversários de Vieira, por ele antecipadas aqui e ali no decorrer de sua pregação, e os labirintos sem saída pelos quais seu raciocínio envereda funcionam como vozes contrárias à tese de trabalho, um contraponto espelhado indo contra a corrente da proposição principal, linha melódica invertida em relação ao "sujeito" da "fuga", uma "fuga-espelho" textual: Vieira

lança um tema e fala do seu oposto, como a criar, em música, uma "fuga invertível", uma "fuga em espelho", como nas composições musicais, apresentando o sujeito de cabeça para baixo, numa inversão. Isto de tal maneira caminha que há uma verdadeira polifonia (SANT'ANNA, 2000, p. 156).

Retórica e espelhamento fazem conluio para dar vazão à pulsão totalizadora do Barroco, que tenta fazer o infinito caber no finito, convulsionando as formas de dentro para fora, com se elas estivessem tomadas pela "intensidade de uma força espiritual que se exerce sobre o corpo, seja para revertê-lo, seja para restabelecê-lo ou para elevá-lo, mas sempre para revolvê-lo e moldar seu interior" (DELEUZE, 1991, p. 15). Vieira e Bach parecem buscar uma geometria para o incapturável turbilhão do mundo, para a inconstância e o descontrole das coisas, realidade recém-descoberta com a complexa e inusitada astronomia kepleriana, com o homem setecentista narcisicamente abalado por não mais se ver no centro do universo e por estar às voltas com a instabilidade e falibilidade dos sistemas humanos: crises políticas, revoluções econômicas, guerras, a peste. Se tudo escapa, se a vida está em fuga, então que ela pelo menos corra acomodada no leito do espelhamento. 


\section{Quadro sinóptico de Vieira e Bach}

\begin{tabular}{l|l}
\hline \multicolumn{1}{c|}{ Vieira } & \multicolumn{2}{c}{ Bach } \\
\hline $\begin{array}{l}\text { O sermão como uma fuga em espelho, em } \\
\text { que são lançadas vozes invertidas em } \\
\text { relação ao mote da prédica. }\end{array}$ & $\begin{array}{l}\text { Uma fuga-espelho é aquela que se } \\
\text { apresenta como uma inversão horizontal } \\
\text { (inversus) em relação a outra tomada } \\
\text { como referência (rectus). }\end{array}$ \\
\hline
\end{tabular}

O sermão visa à captura do ouvinte A fuga engendra em si mesma um projeto através de um constante retorno à tese de convencimento baseado na após cada expansão argumentativa reminiscência permanente do tema, cujas frustrada: expostas todas as variações, só reverberações são "resolvidas" no final. resta à platéia convencer-se da solução apresentada.

A concreção da imagem nos sermões. $\quad$ A concreção do tema na fuga.

O sermão é como uma sala de espelhos, A fuga é como uma sala de espelhos, em em que a realidade bíblica espelha a que vozes espelhadas (totalmente realidade humana. invertidas) e "semi" espelhadas (alusivas) "refletem" o tema.

O desenvolvimento do sermão é O desenvolvimento da fuga consiste em comparável a ondas concêntricas, como produzir ecos imitadores do tema, que encarecimentos sucessivos, de menor para variam desde as reverberações mais maior, buscando em múltiplos reflexos o simples (ou próximas) até as mais comentário alusivo ao caso presente; uma complexas (ou distantes), numa constante mesma idéia central vai adquirindo corpo alusão à matriz temática. "O processo e se complexificando, abrindo-se ao longo musical chamado fuga pode ser de vários parágrafos; estrutura e comparado [...] ao desabrochar de um andamento de natureza analógica, pelo botão de rosa, que já é a rosa" (KIEFER, "exemplo" e pela metáfora, "uma perpétua 1981, p. 205). Estrutura e andamento de novidade sem nada de novo". natureza analógica, portanto, em que as vozes são analogias feitas ao mote inicial. A fuga trabalharia "sobre oposições defasadas que procedem por variações imitativas sem desenvolvimento" (WISNIK, 1989, p. 154), que é o mesmo que "uma perpétua novidade sem nada de novo".

Abstract

When trying to handle reality's turmoil, Vieira's and Bach's rhetoric accomodates the world in the shape of mirroring, through which a comfortable symmetry allows the elusive whirl to be controlled. These two masters' virtuosity shows how repetition and difference can live together in a project of explanation of the world.

Keywords: Vieira. Bach. Rhetoric. Mirroring. 
Referências

DELEUZE, Gilles. A dobra: Leibniz e o barroco. 2. ed. Trad. Luiz B. L. Orlandi. Campinas: Papirus, 1991.

GENETTE, Gérard. Figuras. Trad. Ivonne Floripes Mantoanelli. São Paulo: Perspectiva, 1972.

HARNONCOURT, Nikolaus. O diálogo musical: Monteverdi, Bach e Mozart. Trad. Luiz Paulo Sampaio. Rio de Janeiro: Jorge Zahar Ed., 1993.

KIEFER, Bruno. História e significado das formas musicais. 4. ed. Porto Alegre: Ed. Movimento, 1981. (Coleção Luís Cosme, 2).

MENDES, João. Vieira e a estética do espelho. Brotéria. Lisboa, v. 91, n. 11, p. 431-444, nov. 1970.

MENDES, João. Vieira, homem vertiginoso. Brotéria. Lisboa, v.91, n. 10, p. 267-279, out. 1970.

PÉCORA, Alcir. O demônio mudo. In: NOVAES, Adauto et al. (Org.). O olhar. São Paulo: Companhia das Letras, 1995.

PÉCORA, Alcir. Teatro do sacramento. São Paulo: Edusp; Campinas: Editora da Unicamp, 1994.

SANT'ANNA, Affonso Romano. Barroco: do quadrado à elipse. Rio de Janeiro: RocCO, 2000.

SARAIVA, António José; LOPES, Óscar. História da literatura portuguesa. Rio de Janeiro: Companhia Brasileira de Publicações, 1969.

VIEIRA, Antônio. Sermões. Organização de Alcir Pécora. São Paulo: Hedra, tomos 1 e 2, 2003.

WISNIK, José Miguel. $O$ som e o sentido: uma outra história das músicas. São Paulo: Companhia das Letras, 1989. 